\title{
Influence of new societal factors on neovascular age-related macular degeneration outcomes
}

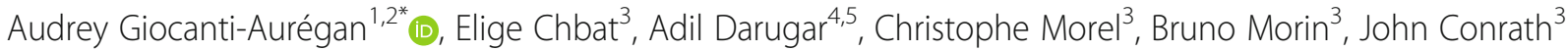 \\ and François Devin ${ }^{3}$
}

\begin{abstract}
Background: To assess the impact of unstudied societal factors for neovascular age-related macular degeneration (nAMD) on functional outcomes after anti-VEGFs.

Methods: Charts of 94 nAMD patients treated in the Monticelli-Paradis Centre, Marseille, France, were reviewed. Phone interviews were conducted to assess societal factors, including transportation, living status, daily reading and social security scheme (SSS). Primary outcome was the impact of family support and disease burden on functional improvement in nAMD.

Results: Between baseline and month 24 (M24), 42.4\% of the variability in best-corrected visual acuity (BCVA) was explained by the cumulative effect of the following societal factors: intermittent out-patient follow-up, marital status, daily reading, transportation type, commuting time. No isolated societal factor significantly correlated with ETDRS BCVA severity at M24. A trend to correlation was observed between the EDTRS score at M24 and the SSS $(P=0.076)$, economic burden $(P=0.075)$, time between diagnosis and treatment initiation $(P=0.070)$. A significant correlation was found for the disease burdensome on the patient $(P=0.034)$ and low vision rehabilitation $(P=0.014)$.
\end{abstract}

Conclusions: Societal factors could influence functional outcomes in nAMD patients treated with anti-VEGFs. They could contribute to the healing process or sustain disease progression.

Keywords: Age-related macular degeneration, Economic burden, Societal factors, Retinal disease

\section{Background}

Age-related macular degeneration (AMD) is the leading cause of blindness in developed countries [1-5] and is responsible for $8.7 \%$ of all blindness worldwide. AMD prevalence is expected to increase with population ageing projections [6]. AMD is a multifactorial and heterogeneous disease and many studies have investigated the effects of environmental factors such as education, socioeconomic status [7], smoking [8, 9], alcohol consumption [10], cardiovascular diseases [11], diet, obesity, oestrogen levels, light exposure, statin and aspirin therapies [12] on AMD development and progression.

\footnotetext{
* Correspondence: audreygiocanti@yahoo.fr

'Department Ophthalmology, Avicenne Hospital, DHU Vision and Handicaps,

125 rue de Stalingrad, 93000 Bobigny, France

${ }^{2}$ Sorbonne Universités, UPMC Univ Paris 06, INSERM, CNRS, Institut de la

Vision, 17 rue Moreau, 75012 Paris, France

Full list of author information is available at the end of the article
}

In a recent study assessing twins, Seddon et al. [13] have suggested that both genetic and environmental proportions of variance were observed for specific macular drusen and retinal pigment epithelial features. In addition, Keilhauer et al. [14] have also suggested that despite genetic risk variants predisposing to AMD, the course and visual outcomes appear to be affected by environmental factors rather than genetic determinants. At the time of our study, neovascular AMD (nAMD) treatment included a monthly monitoring and/or injections requiring a scheduling for patients and caregivers, and resulting in a significant burden on patients and their family. This therapeutic scheme involves new societal factors that may influence the course and functional outcomes of nAMD patients treated with anti-VEGFs.

While numerous studies agree on the effect of the above-mentioned environmental factors, our study 
investigated the influence of new societal factors that are mainly related to anti-VEGF therapy. The aim of this study was to assess the impact of these new anti-VEGF-related societal factors on functional outcomes in nAMD patients.

\section{Methods}

\section{Setting}

The study was conducted in a tertiary care centre specialised in diagnosis and treatment of macular diseases, located in Marseille, France.

\section{Study design}

The study was a retrospective analysis of patient charts treated for nAMD in the Monticelli Clinic with antiVEGF intravitreal injections between October 2010 and October 2012 in a real-life setting. The societal data were obtained by phone interview. This study was conducted in accordance with the tenets of the Declaration of Helsinki, and an informed consent was obtained from subjects. Approval was obtained from the France Macula Federation ethical committee.

\section{Eligibility criteria}

Consecutive patients diagnosed with nAMD, treated with anti-VEGF (ranibizumab) before October 2010 with a follow-up in the Monticelli Clinic of at least 2 years between October 2010 and October 2012, were included in this analysis. Patients who were not injected exclusively in the Monticelli Clinic and patients with other ocular disease responsible for vision loss were excluded.

\section{Methods}

All patients were initially examined by an independent technician using an Early Treatment Diabetic Retinopathy Study (ETDRS) chart at baseline (October 2010) and their best-corrected visual acuity (BCVA) was regularly measured for 2 years. The visual outcomes assessed were baseline and final BCVA (M24) and change in BCVA during the study. The number of intravitreal injections received during this time was recorded. Another independent technician conducted phone interviews to assess parameters of interest: intermittent outpatient follow-up (yes/no), living status (in couple, with family or alone), type of vehicle used to come to the Monticelli Centre (taxi, public transportation, own vehicle, ambulance), commuting time (0-1 h; 1-2 h; more than $2 \mathrm{~h}$ ); low vision rehabilitation (yes/no); daily reading type (journal, book, computer, none); healthcare system covering all expenses (yes/no); economic benefits of social security scheme (10-point scale) and the burdensome of the consultation for the patient (0-10-point analogic scale). We also collected patient complaints about their follow-up and treatment.

\section{Treatment regimen}

All patients received ranibizumab injections at the Monticelli centre. After 3 loading-dose injections, patients were treated on an as needed basis. The as-needed treatment was administered if the patient had any of the following criteria in the study eye: loss of 5 or more letters of BCVA; new, recurrent or persistent subretinal or intraretinal fluid based on OCT; or new macular hemorrhage. The patients were monitored monthly by BCVA on ETDRS chart, retinography and time domain OCT.

\section{Data analysis}

All statistical analyses were performed using XLSTAT version 2015. A Chi square analysis or Fisher's exact test was used to assess the relationship between the BCVA score at M24 or the change in BCVA (on the ETDRS scale) over 24 months and all the above-mentioned societal factors. For the ANCOVA/multivariate unconditional logistic regression analysis, patients were divided into 2 independent groups: patients whose BCVA score evolved positively, and patients whose BCVA evolved negatively. $P$-values at $95 \%$ confidence interval $[\mathrm{CI}]$ for the chi square analysis or Fisher's exact test were examined, as well as the coefficient of determination $\mathrm{R}^{2}$, analysis of covariance, model parameters, standardised coefficients at lower and upper limits (95\%) using an ANCOVA analysis, for each demographic variable related to the BCVA score and evolution. Number of injections, age and baseline BCVA were controlled in the ANCOVA analysis.

The primary endpoint was to assess the impact of all the above-mentioned new societal factors on the BCVA at M24 and change in BCVA over 24 months.

\section{Results}

Ninety-four patients with a mean age $( \pm \mathrm{SD})$ of $77( \pm 8.42)$ years were included in the study. The mean BCVA at baseline was of $58.35 \pm 13.65$ letters, the mean variation over 2 years was of $-7.5 \pm 10$ letters (Min: -58 ; Max: +17 ), and the mean final BCVA was of $50.85 \pm 11.8$ letters. Patients have received a mean of $8.84 \pm 3.9(\mathrm{Min}=1$; $\max =21)$ injections before inclusion in the study, and received $6.74 \pm 3.9$ ( $\operatorname{Min}=0 ; \max =22)$ injections during the 2-year follow-up. There was no statistically significant association between the severity of the disease, measured with the final ETDRS score at M24 (October 2012) and the following demographic variables: intermittent outpatient follow-up $(P=0.821)$, family status $(P=0.564)$, daily reading $(P=0.180)$, commuting time to the clinic $(0.782)$ and transport type $(P=0.743)$. However, a trend to dependence was observed between the BCVA at M24, and social security scheme $(P=0.083)$, and economic burden of the treatment $(P=0.075)$. Low vision rehabilitation $(P=0.014)$ and burdensome of the consultation for the patient $(P=0.034)$, significantly correlated with BCVA severity at M24. Also, the time between the diagnosis and the 
Table 1 Societal data for patients with a negative evolution of their ETDRS score over 24 months of follow-up (78.2\% of patients): For negative ETDRS score evolution: 1 corresponds to changes between -10 and -5 letters; 2 corresponds to changes between -5 and 0

Variable
Negative ETDRS Score evolution
baseline and M24

Outpatient follow-up

Family status

Transportation to the clinic

Commuting time to the clinic

Low vision rehabilitation

Daily reading

Health assurance covering $100 \%$ of expenses

$\begin{array}{ll}\text { Categories } & \text { Percentage } \\ 1 & 65.574 \\ 2 & 34.426 \\ 0 & 21.311\end{array}$

$\begin{array}{ll}1 & 13.115 \\ 2 & 4.918 \\ 3 & 13.115 \\ 4 & 8.197 \\ 5 & 6.557 \\ 6 & 6.557 \\ 7 & 6.557 \\ 8 & 3.279 \\ 9 & 1.639 \\ 10 & 3.279 \\ 12 & 3.279 \\ 16 & 1.639 \\ 17 & 1.639 \\ 19 & 1.639 \\ 20 & 1.639 \\ 22 & 1.639\end{array}$

No -80.328

Yes $\quad 16.393$

Sometimes $\quad 3.279$

Couple $\quad 52.459$

Living alone $\quad 45.902$

Family $\quad 1.639$

Medicalised vehicle $\quad 40.984$ Taxi $\quad 6.557$

Public transportation $\quad 3.279$

Personal car $\quad 47.541$

Walking $\quad 1.639$

0 to $1 \mathrm{~h} \quad 42.623$

1 to $2 \mathrm{~h} \quad 42.623$

More than $2 \mathrm{~h} \quad 14.754$

No $\quad 88.525$

Yes $\quad 11.475$

None $\quad 27.869$

Journal $\quad 29.508$

Books $\quad 32.787$

Computer $\quad 9.836$

No $\quad 34.426$

Table 1 Societal data for patients with a negative evolution of their ETDRS score over 24 months of follow-up (78.2\% of patients): For negative ETDRS score evolution: 1 corresponds to changes between -10 and -5 letters; 2 corresponds to changes between -5 and 0 (Continued)

\begin{tabular}{lll}
\hline Variable & Categories & Percentage \\
\hline Economic burden of the treatment & 1 & 65.574 \\
on the patient (0-10 scale) & & 4.918 \\
& 2 & 13.115 \\
& 3 & 19.672 \\
& 4 & 6.557 \\
& 5 & 24.590 \\
& 6 & 9.836 \\
Painfulness of the treatment burden & 1 & 18.033 \\
(0-10 scale) & 7 & 3.279 \\
& 8 & 8.197 \\
& 2 & 16.393 \\
& 3 & 29.508 \\
& 4 & 9.836 \\
& 5 & 21.311 \\
& 6 & 9.836 \\
& 7 & 1.639 \\
8 & 1.639 \\
& 10 & 1.639 \\
\hline
\end{tabular}

initiation of the treatment tended to correlate with the BCVA score at M24 $(P=0.070)$. The injection number during the 2-year follow-up was not related to BCVA severity at M24 $(P=0.999)$.

Regarding the link between each demographic factor and the change in ETDRS score over 2 years (between baseline and M24), no significant correlation was observed with: intermittent outpatient follow-up $(P=0.943)$, family status $(P=0.308)$, daily reading $(P=0.752)$, commuting time to the clinic $(P=0.175)$, transport type $(P=0.157)$, security social scheme $(P=0.129)$, score of the consultation burdensome for the patient $(P=0.468)$, economic burden of the treatment $(P=0.654)$, and low vision rehabilitation $(P=0.176)$. The number of injections required was not significantly related to the change in ETDRS between baseline and M24 $(P=0.128)$. The distribution of the different variables is summarized in Table 1 (and Additional file 1) for patients with a negative evolution of their ETDRS score over the 24-month followup, and in Table 2 (and Additional file 1) for those with a positive evolution of their ETDRS score. The model comparing the weight of the different variables on the change in ETDRS score over 24 months is represented in Fig. 1(and Additional file 1). 
Table 2 Societal data for patients with a positive evolution of their ETDRS score over 24 months of follow-up (21.8\% of patients): for positive ETDRS score evolution (first line): 3 corresponds to changes between 0 and +5 letters; 4 corresponds to changes between +5 and +10 letters

\begin{tabular}{|c|c|c|}
\hline Variable & Categories & Percenta \\
\hline \multirow[t]{2}{*}{ Positive ETDRS Score evolution } & 3 & 70.588 \\
\hline & 4 & 29.412 \\
\hline \multirow{10}{*}{$\begin{array}{l}\text { Number of injections between } \\
\text { baseline and M24 }\end{array}$} & 0 & 5.882 \\
\hline & 2 & 5.882 \\
\hline & 5 & 17.647 \\
\hline & 6 & 29.412 \\
\hline & 8 & 5.882 \\
\hline & 9 & 5.882 \\
\hline & 10 & 5.882 \\
\hline & 14 & 11.765 \\
\hline & 15 & 5.882 \\
\hline & 17 & 5.882 \\
\hline \multirow[t]{3}{*}{ Outpatient follow-up } & No & 88.235 \\
\hline & Yes & 5.882 \\
\hline & Sometimes & 5.882 \\
\hline \multirow[t]{3}{*}{ Family status } & Couple & 41.176 \\
\hline & Living alone & 52.941 \\
\hline & Family & 5.882 \\
\hline \multirow[t]{4}{*}{ Transportation to the clinic } & Medicalized vehicle & 52.941 \\
\hline & Taxi & 23.529 \\
\hline & Public transportation & 5.882 \\
\hline & Personal car & 17.647 \\
\hline \multirow[t]{3}{*}{ Commuting time to the clinic } & 0 to $1 \mathrm{~h}$ & 47.059 \\
\hline & 1 to $2 \mathrm{~h}$ & 47.059 \\
\hline & More than $2 \mathrm{~h}$ & 5.882 \\
\hline \multirow[t]{2}{*}{ Low vision rehabilitation } & No & 94.118 \\
\hline & Yes & 5.882 \\
\hline \multirow[t]{4}{*}{ Daily reading } & None & 11.765 \\
\hline & Journal & 58.824 \\
\hline & Books & 23.529 \\
\hline & Computer & 5.882 \\
\hline \multirow{2}{*}{$\begin{array}{l}\text { Health assurance covering } \\
100 \% \text { of expenses }\end{array}$} & No & 29.412 \\
\hline & Yes & 70.588 \\
\hline \multirow{6}{*}{$\begin{array}{l}\text { Economic burden of the treatment } \\
\text { on the patient ( } 0-10 \text { scale) }\end{array}$} & 2 & 5.882 \\
\hline & 3 & 17.647 \\
\hline & 4 & 29.412 \\
\hline & 5 & 17.647 \\
\hline & 6 & 17.647 \\
\hline & 7 & 5.882 \\
\hline
\end{tabular}

Table 2 Societal data for patients with a positive evolution of their ETDRS score over 24 months of follow-up (21.8\% of patients): for positive ETDRS score evolution (first line): 3 corresponds to changes between 0 and +5 letters; 4 corresponds to changes between +5 and +10 letters (Continued)

\begin{tabular}{lll}
\hline Variable & Categories & Percentage \\
\hline & 8 & 5.882 \\
Painfulness of the treatment burden & 2 & 17.647 \\
(10 scale) & & \\
& 3 & 11.765 \\
& 4 & 23.529 \\
& 5 & 17.647 \\
& 6 & 5.882 \\
& 7 & 17.647 \\
& 8 & 5.882 \\
\hline
\end{tabular}

However, the ANCOVA analysis showed that $42.4 \%$ of the variability of the change in BCVA score between baseline and M24 was explained by the cumulative effect of all studied factors. The remaining variability was due to some other effects (other variables) that were not analysed in this study. Comparative effects of the weight of individual variables in the cohort of patients whose BCVA score improved (Fig. 2 and Additional file 1) and those whose BCVA score worsened (Fig. 3 and Additional file 1) at the end of the follow-up (M24) were studied.

Type I and Type III sum of square analysis showed that the treatment burdensome, low vision rehabilitation and daily reading variables provided the least information to the model (Fig. 1). It should be noted that the corresponding confidence interval included 0 , confirming the relatively weak impact of each environmental factor taken separately on the change in BCVA. Regarding the clinical follow-up variable, it appeared that for a given injection number, the fact to be exclusively followed at the clinic was associated with a better change in BCVA than an intermittent outpatient follow-up. Living alone or in couple decreased the change in BCVA score over 24 months, compared to living with their family. Ambulance or taxi transportation contributed more to the increase in BCVA score than car or public transportation. We also found that a commuting time exceeding $2 \mathrm{~h}$ led to better effect than a shorter commuting time. Patients who used to read daily had a slight decrease in BCVA improvement compared to patients who did not read daily. Patients who paid their treatments themselves (no healthcare insurance) showed a trend to a higher BCVA gain than those who did not.

The main complaints of patients were the long waiting time before consultation ( $40 \%$ of patients), the cost of consultations and transport (30\% of patients), the stress 


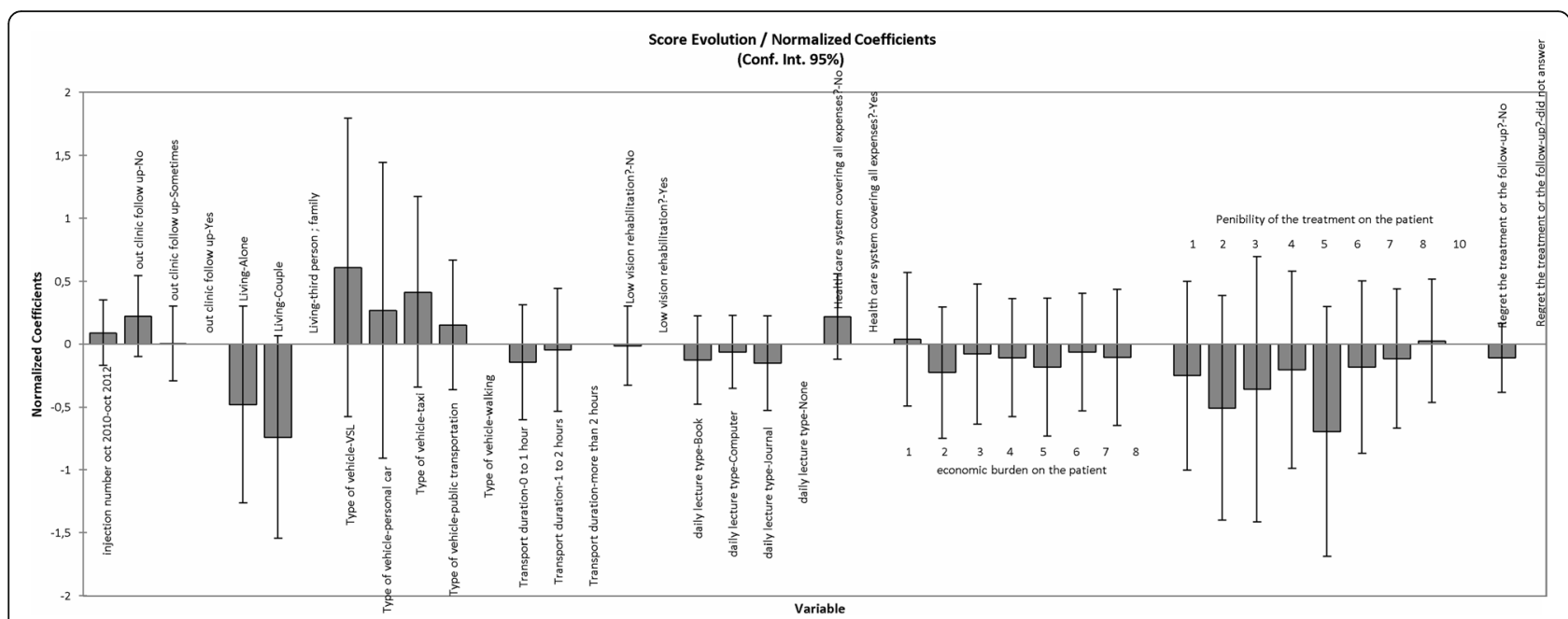

Fig. 1 Graphical representation of the model assessing the weight (coefficient) of each variable on the change in ETRDS score over 24 months

due to the injection and the unknown prognosis. Only one patient regretted having received this therapy because of these discomforts.

\section{Discussion}

In our study, the ANCOVA analysis showed that $42.4 \%$ of the variability of the change in BCVA score from baseline could be explained by the cumulative effect of all studied factors. The remaining variability was due to other previously described environmental variables ${ }^{7-16}$ that were not analysed in this study. Because of the obvious evidence of the role of environmental factors in disease progression, our approach was to identify yet unknown societal factors that could influence nAMD evolution in patients treated with anti-VEGF therapy. These new factors appeared with the burden due to the need for monthly examination and/ or treatment burden related to anti-VEGF therapy.

The large variability of factors influencing the healing process may explain why the variables assessed independently in our study did not provide a significant amount of information to the model. Since societal factors could have an impact on the healing process, population studies assessing these new societal criteria are needed [15]. Our study is, to the best of our knowledge, one of the first to investigate the impact of these new societal criteria, including intermittent outpatient follow-up, family status, type of transportation, commuting time, low vision rehabilitation, daily reading type, healthcare system, economic benefits of the social security scheme and the burdensome of the consultation on the nAMD patient treated with anti-VEGF therapy. Interestingly, patients with a large amount of

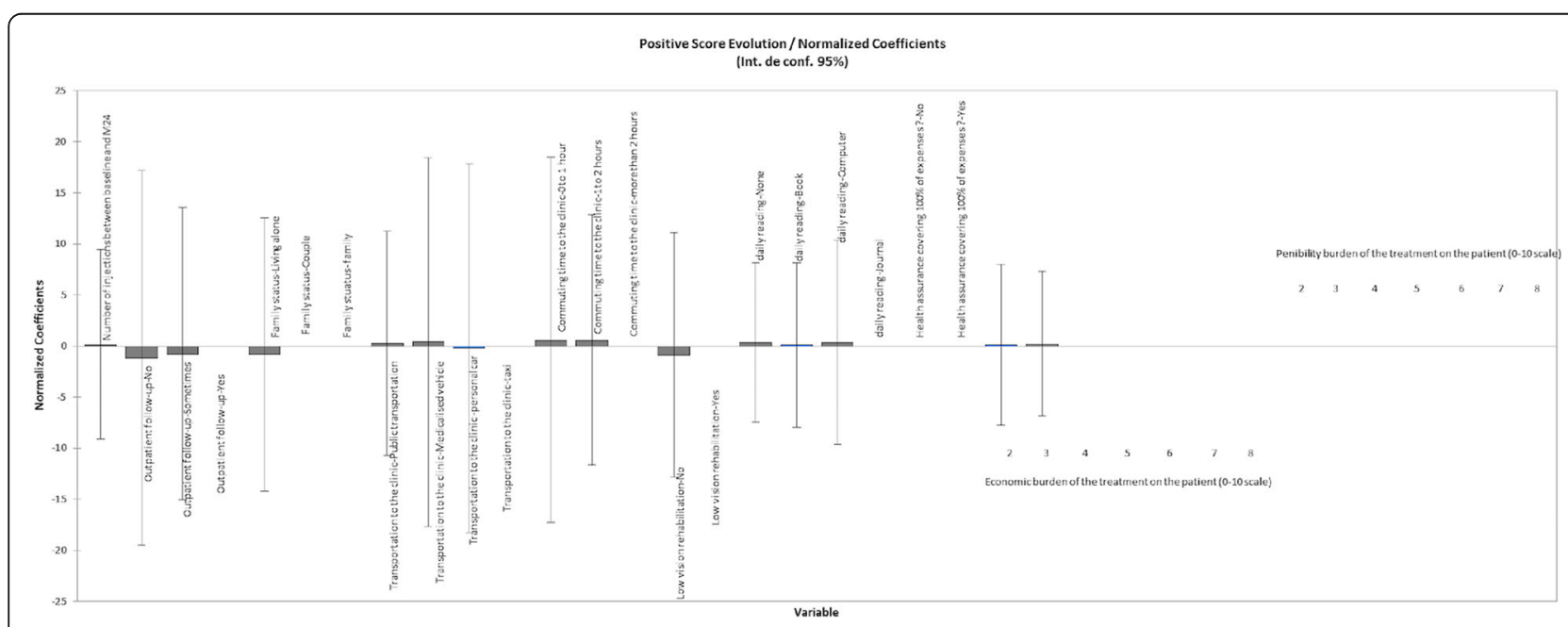

Fig. 2 Graphical representation of the model assessing the weight (coefficient) of each variable on the change in ETRDS score over 24 months in the subgroup of nAMD patients who gained vision over 24 months 


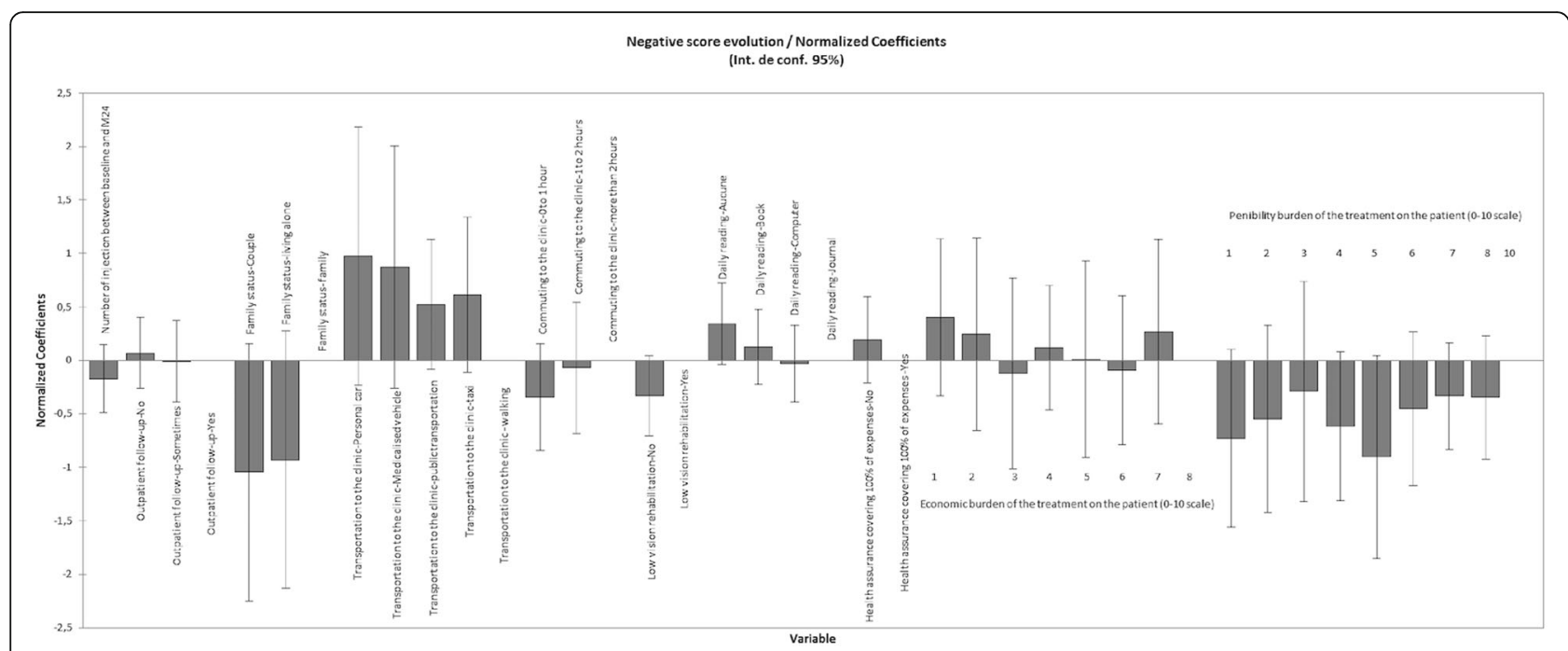

Fig. 3 Graphical representation of the model assessing the weight (coefficient) of each variable on the change in ETRDS score over 24 months in the subgroup of nAMD patients who lost vision over 24 months

painfulness due to the treatment (long commuting time, no healthcare insurance) seem to have better outcomes, probably because of a higher motivation and involvement in their treatment. Surprisingly, patients who reported having experienced pain related to the treatment also had a better BCVA gain than patients who did not. This is unexpected because it has been already reported that there is a relationship between pain and depression [16], between mood and sleep disorders and chronic pain [17], and finally that nAMD patients treated by antiVEGF experience a certain level of anxiety and depression [18]. It is also known that anxiety and depression could have a negative impact on the healing process of somatic diseases [19]. We can suggest in our study that the placebo effect in addition to the physiologic effect of antiVEGF therapy is higher when the injection is painful. Modulating a disease, which is partially determined by genetic risk factors, by societal factors is indeed possible and has already been shown in other diseases such as diabetes [20].

Investigating these parameters is essential because nAMD seems to be associated with depression or induce mood disorders [21] like numerous chronic diseases. All the factors analysed in this study could also lead to depression, including the family status or intermittent outpatient follow-up for instance. But depression or depressive mood could not only play a negative role on the healing process per se but also have a negative impact on the compliance with treatment, which could be detrimental to the functional outcomes at the end of the study. In this study, we eliminated the bias that these depression-related factors could introduce in terms of treatment discontinuation by excluding patients who did not complete the 2-year follow-up when they were exclusively followed in the clinic but it was not possible to exclude patients who were partially followed outside the clinic. Patient compliance could be one of the causes of lower BCVA gains in case of follow-up outside the clinic, but it could also be due to the longer access to treatment. Moreover, studies have shown that depression could maintain the disease process in chronic diseases [22-24]. Furthermore, it has been shown that neighbourhood deprivation is associated with age-related eye diseases [25], however, in nAMD, all the impacts of these factors remain to be elucidated and could be an important aspect to consider in patient treatment plan.

Another important aspect of these results is that the factors we studied could influence self-administered quality of life questionnaires used in nAMD studies. The assessment by patients themselves of their own quality of life could be biased by direct benefits from these factors, including the systematic use of an ambulance or the fact to be surrounded by their family at the time of the monthly consultations. Conversely, the self-assessment could be altered by the negative perception due to the heavy burden of the treatment. These elements should be kept in mind when interpreting quality of life scores in chronic diseases, especially in nAMD.

We might also wonder whether there might not be a bias in the studied population which is from the South of France where habits and family organization are different from those of the North of France and probably from other countries but are more representative of the family organization of Mediterranean countries, where a family circle is often present, the commuting time to the clinic is longer and the need for car use is frequent.

Finally, we can notice that the VA gain along the study is very lower than other studies such as the AURA study [26] for instance, -7.5 letters in ours versus +4.1 letters 
[26] at 2 years. We can assume that the reasons could be that our study includes patients a long time prior the AURA study (2010-2012) when the regimen of treatment in the real-life was less intensive than nowadays [27]; our baseline BCVA was slightly higher (58.35 versus 55 letters), and we did not include patients at the time of diagnosis but in October 2010 in order to assess the societal factors at the same period (October 2010-October 2012) for all patients, so we can have miss in our interval of follow-up the first months of treatment usually associated with the higher gain for patient. However the aim of our study was not to describe visual outcomes, but the impact of societal factors on maintaining visual gain over time in nAMD patients treated with antiVEGF.

\section{Conclusions}

Societal factors seem to play an important yet unclear role in the course and functional outcomes in nAMD patients treated with anti-VEGFs. They may either contribute to the healing process or sustain the disease process together with stress or depression. Further studies will be needed to confirm our findings and identify all of these factors.

\section{Additional file}

Additional file 1: Raw data: categories and frequencies of each different variable and model parameter values showing the coefficients of the different categories of each variable. (ODT $6 \mathrm{~kb}$ )

\begin{abstract}
Abbreviations
Anti-VEGF: Anti- vascular endothelial growth factor; BCVA: Best corrected visual acuity; DNA: Deoxyribonucleic acid; ETDRS: Early treatment diabetic retinopathy study; nAMD: Neovascular age-related macular degeneration
\end{abstract}

\section{Acknowledgements}

$\mathrm{AVOPH}$

\section{Funding}

AVOPH (association for Vision in ophthalmology- Avicenne hospital).

\section{Availability of data and materials}

The datasets generated and analyzed during the current study are available in the "Raw data" repository, as supplementary material.

\section{Authors' contributions}

AGA has collected data and has been involved in drafting the manuscript and revising it critically for important intellectual content. EC has collected data and helped for data analysis and in drafting the manuscript. BRM has collected data and helped revising the draft critically for important intellectual content. CGHM has made substantial contributions in analysis and interpretation of data. JGC contributed to data analysis and interpretation and helped revising the draft critically for important intellectual content. FCD has contributed to data analysis and interpretation and helped revising the draft critically for important intellectual content. $A D$ has contributed to data analysis and interpretation and helped revising the draft critically for important intellectual content. All the authors read and approved the final manuscript.

\section{Ethics approval and consent to participate}

This study was conducted in accordance with the tenets of the Declaration of Helsinki, and an informed consent was obtained from subjects. Approval was obtained from the France Macula Federation ethical committee.
Consent for publication

An informed consent was obtained from the patient.

\section{Competing interests}

Audrey Giocanti-Aurégan is consultant for Alimera, Allergan, Bayer and Novartis. Adil Darugar is consultant for Bayer and Novartis. Elige Chbat has nothing to disclose. François Devin, Christophe Morel, Bruno Morin are consultants for Alimera, Allergan, Bayer and Novartis, Roche, Ophtotec, Thea, Alcon, Zeiss. John Conrath is consultant for Alimera, Allergan, Bayer and Novartis, Roche, Ellex, Alcon

\section{Publisher's Note}

Springer Nature remains neutral with regard to jurisdictional claims in published maps and institutional affiliations.

\section{Author details}

${ }^{1}$ Department Ophthalmology, Avicenne Hospital, DHU Vision and Handicaps, 125 rue de Stalingrad, 93000 Bobigny, France. ${ }^{2}$ Sorbonne Universités, UPMC Univ Paris 06, INSERM, CNRS, Institut de la Vision, 17 rue Moreau, 75012 Paris, France. ${ }^{3}$ Ophthalmology Center Paradis Marseille, 433 rue Paradis, 13008 Marseille, France. ${ }^{4}$ Pitié Salpêtrière Hospital, Ophthalmology, DHU Vision and Handicaps, 47-83 Bd de l'Hôpital, 75013 Paris, France. ${ }^{5}$ Oise Ophthalmology, 6 Avenue du Poteau, 60300 Chamant, France.

Received: 30 January 2017 Accepted: 23 January 2018

Published online: 01 February 2018

\section{References}

1. Klein R, Klein BE, Cruickshanks KJ. The prevalence of age-related maculopathy by geographic region and ethnicity. Prog Retin Eye Res. 1999; 18:371-89.

2. Mitchell P, Smith W, Attebo K, Wang JJ. Prevalence of age-related maculopathy in Australia. The Blue Mountains eye study. Ophthalmology. 1995;102:1450-60.

3. Klaver CC, Assink JJ, van Leeuwen R, Wolfs RC, Vingerling JR, Stijnen T, et al. Incidence and progression rates of age-related maculopathy: the Rotterdam study. Invest Ophthalmol Vis Sci. 2001;42:2237-41.

4. Kawasaki R, Yasuda M, Song SJ, Chen S-J, Jonas JB, Wang JJ, et al. The prevalence of age-related macular degeneration in Asians: a systematic review and meta-analysis. Ophthalmology. 2010;117:921-7.

5. Wong TY, Wong T, Chakravarthy U, Klein R, Mitchell P, Zlateva G, et al. The natural history and prognosis of neovascular age-related macular degeneration: a systematic review of the literature and meta-analysis. Ophthalmology. 2008:115:116-26.

6. Ruiz-Moreno JM, Coco RM, García-Arumí J, Xu X, Zlateva G. Burden of illness of bilateral neovascular age-related macular degeneration in Spain. Curr Med Res Opin. 2008;24:2103-11.

7. Cackett P, Tay WT, Aung T, Wang JJ, Shankar A, Saw SM, et al. Education, socio-economic status and age-related macular degeneration in Asians: the Singapore Malay eye study. Br J Ophthalmol. 2008;92:1312-5.

8. Kelly SP, Edwards R, Elton P, Mitchell P. Age related macular degeneration: smoking entails major risk of blindness. BMJ. 2003;326:1458-1459-1460.

9. Thornton J, Edwards R, Mitchell P, Harrison RA, Buchan I, Kelly SP. Smoking and age-related macular degeneration: a review of association. Eye Lond Engl. 2005;19:935-44.

10. Aoki A, Inoue M, Nguyen E, Obata R, Kadonosono K, Shinkai S, et al. Dietary n-3 fatty acid, a-Tocopherol, zinc, vitamin D, vitamin C, and $\beta$ carotene are associated with age-related macular degeneration in Japan. Sci Rep. 2016;6:20723.

11. Wang SB, Mitchell P, Chiha J, Liew G, AJH P, Thiagalingam A, et al. Severity of coronary artery disease is independently associated with the frequency of early age-related macular degeneration. Br J Ophthalmol. 2015;99:365-70.

12. Orban T, Johnson WM, Dong Z, Maeda T, Maeda A, Sakai T, et al. Serum levels of lipid metabolites in age-related macular degeneration. FASEB J Off Publ Fed Am Soc Exp Biol. 2015;29:4579-88

13. Seddon JM, Reynolds R, Maller J, Fagerness JA, Daly MJ, Rosner B. Prediction model for prevalence and incidence of advanced age-related macular degeneration based on genetic, demographic, and environmental variables. Invest Ophthalmol Vis Sci. 2009;50:2044-53. 
14. Keilhauer CN, Fritsche LG, BHF W. Age-related macular degeneration with discordant late stage phenotypes in monozygotic twins. Ophthalmic Genet. 2011;32:237-44.

15. Anand A, Sharma K, Chen W, Sharma NK. Using current data to define new approach in age related macular degeneration: need to accelerate translational research. Curr Genomics. 2014;15:266-77.

16. Von Korff M, Simon G. The relationship between pain and depression. Br J Psychiatry Suppl. 1996;(30):101-8.

17. Ojeda B, Salazar A, Calahorro MJ, Dueñas M, Mico JA, de Sola H, et al. Understanding the different relationships between mood and sleep disorders in several groups of non-oncological patients with chronic pain. Curr Med Res Opin. 2017. p 1-8.

18. Senra H, Balaskas K, Mahmoodi N, Aslam T. Experience of anti-VEGF treatment and clinical levels of depression and anxiety in patients with wet age-related macular degeneration. Am J Ophthalmol. 2017:177:213-24.

19. Kiecolt-Glaser JK, McGuire L, Robles TF, Glaser R. Emotions, morbidity, and mortality: new perspectives from psychoneuroimmunology. Annu Rev Psychol. 2002;53:83-107.

20. Zimmet P, Alberti KG, Shaw J. Global and societal implications of the diabetes epidemic. Nature. 2001:414:782-7.

21. Dawson SR, Mallen CD, Gouldstone MB, Yarham R, Mansell G. The prevalence of anxiety and depression in people with age-related macular degeneration: a systematic review of observational study data. BMC Ophthalmol. 2014;14:78

22. Espahbodi F, Hosseini H, Mirzade MM, Shafaat AB. Effect of psycho education on depression and anxiety symptoms in patients on Hemodialysis. Iran J Psychiatry Behav Sci. 2015;9:e227.

23. Sharma P, Morris NR, Adams L. Effect of experimental modulation of mood on perception of exertional dyspnea in healthy subjects. J Appl Physiol Bethesda Md 1985. 2016;120:114-120.

24. Descalzi G, Ikegami D, Ushijima T, Nestler EJ, Zachariou V, Narita M. Epigenetic mechanisms of chronic pain. Trends Neurosci. 2015;38:237-46.

25. Hamano T, Li X, Tanito M, Nabika T, Shiwaku K, Sundquist J, et al. Neighborhood deprivation and risk of age-related eye diseases: a follow-up study in Sweden. Ophthalmic Epidemiol. 2015;22:308-20.

26. Hykin P, Chakravarthy U, Lotery A, McKibbin M, Napier J, Sivaprasad S. A retrospective study of the real-life utilization and effectiveness of ranibizumab therapy for neovascular age-related macular degeneration in the UK. Clin Ophthalmol AuckI NZ. 2016;10:87-96.

27. Cohen SY, Dubois L, Ayrault S, Dourmad P, Delahaye-Mazza C, Fajnkuchen F, et al. Ranibizumab for exudative AMD in a clinical setting: differences between 2007 and 2010. Graefes Arch Clin Exp Ophthalmol Albrecht Von Graefes Arch Klin Exp Ophthalmol. 2013;251:2499-503.

\section{Submit your next manuscript to BioMed Central and we will help you at every step:}

- We accept pre-submission inquiries

- Our selector tool helps you to find the most relevant journal

- We provide round the clock customer support

- Convenient online submission

- Thorough peer review

- Inclusion in PubMed and all major indexing services

- Maximum visibility for your research

Submit your manuscript at www.biomedcentral.com/submit

CBiomed Central 